\title{
ADAPTATION OF THE PUPIL LIGHT REFLEX
}

\author{
N. OHBA ${ }^{1}$ and M. ALPERN \\ Vision Research Laboratory, Departments of Ophthalmology and Physiology, \\ University of Michigan, Ann Arbor, Michigan 48104
}

(Received 9 October 1971)

\section{INTRODUCTION}

THE RECEPTORS which catch the quanta and thereby give rise to a change in pupil size are no doubt, those with which we see, (Alpern and Benson, 1953; AlPERN and Camprell, 1962; ALEXANDRIDIS and KOEPPE, 1969). But, in man, the nerve pathways for vision include the striate cortex, while those for the pupil light reflex involve only midbrain nuclei. How and where do these pathways separate? Are there separate channels in the retina and optic nerve, or does each (or some) nerve fiber(s) bifurcate within the optic tract, sending one bifurcated fiber to the thalamus (for vision) and the other to the pretectal nucleus (for pupil constriction)? Although the latter is the more economical alternative, experimental evidence on man which can shed important light on this question is not easy to imagine.

One approach is to study the changes in sensitivity produced by bleaching and by backgrounds. There is now a body of quite convincing psychophysical evidence (cf. a good summary by RusHTON, 1965a) that the threshold changes during adaptation represent changes in neural processing rather than merely changes in visual pigment as had once been supposed. Are adaptation processes similar for vision and photopupillary motion?

In the previous paper (ALPERN and OHBA, 1972), we studied the effects of bleaching and backgrounds on pupil size in the steady state. It was found that the model used by RUSHToN (1965a) for visual adaptation could be applied to predict reasonably well the diameter of the pupil at equilibrium during uniform ganzfeld illumination. The clear implication of this application is that the regulation of photopupillary sensitivity by backgrounds and by bleaching follow the same rules as the regulation of visual sensitivity. In the present paper we examine this implication at some length.

ALPEKN, KIrAa and IsAacson (1959) found for bleaching backgrounds, as have a number of investigators (SCHWEITZER and Bouman, 1958; AleXANDridIs and DODT, 1967; SCHUBERT and Thoss, 1967; WeBster, COHEN and Boynton, 1968; AleXANDRIDIS and KoEPPE, 1969; WEBSTER, 1971) for real backgrounds, that the threshold for a criterion photopupil response varies systematically in ways quite analogous to the visual threshold. Some of these experiments have been cricitized for a variety of reasons (BRECHER, 1959) and there are inconsistencies in the results of some of the others. In the first part of this paper, we confirm the essential results of these earlier investigations under stimulus conditions (including full field uniform retinal illumination with pupil size fixed) which obviatc as many sources of error as possible. We find that, as in vision, the threshold for the pupil response is elevated in a similar way by bleaching and by real backgrounds. In the second part, we

\footnotetext{
${ }^{1}$ On leave from the Department of Ophthalmology, University of Tokyo, Tokyo, Japan.
} 
show that this depression of sensitivity can be quantified by the construct of the equivalent background of the bleach employed by STILEs and CRAWFORd (1932), Crawford (1947), and by RusHron (1965a) to describe psychophysical results. Finally, this pupillomotor equivalent background is shown to agree well with its psychophysical counterpart. The simplest explanation is that the nerve pathways for the consensual pupil light refiex and for threshold vision stay together at least through the stages in the neural pathways in which sensitivity regulation in adaptation has been achieved.

\section{METHOD}

The experimental arrangement is shown in Fig. 1. Throughout, a test flash and the adapting light were given to the right eye and consensually evoked photopupil response was recorded from the left. The test flash was a 50W Xenon electronic flash (Mighty Lite, Model No. 1) (S1). A tungsten ribbon filament (6 V-

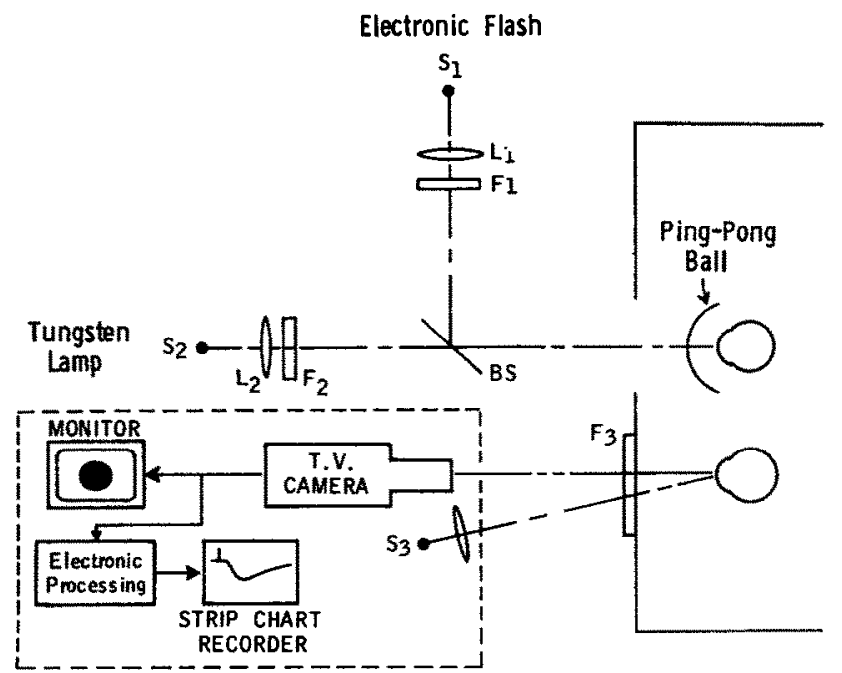

FIG. 1. Line drawing of the experimental apparatus as seen from above. The left eye is shielded from stray light from the stimulus background and test flash by masks which are not shown. $S_{1}$ is an electronic (Xenon) flash serving as test and $S_{2}$ a tungsten ribbon, the image of which covers the surface of the half ping-pong ball over the right eye. The pupil of the right eye is dilated with tropicamide. $F_{1}$ and $F_{2}$ represent "neutral" density (Wratten No. 96), and-in some cases-colored gelatin, filters, $F_{3}$ is an infra-red transmitting (Wratten No. 89) filter which absorbs essentially all the visible light incident on it. $S_{3}$ is a small tungsten lamp which illuminates the anterior segment of the left eye.

$18 \mathrm{amp}$ ) (S2) was used for light adaptation experiments. The intensity of these lights was varied with Kodak Wratten 96 "neutral" density filters. Another tungsten source from a $300 \mathrm{~W} \mathrm{2.5}$ amp lamp of a slide projector (not shown in Fig. 1) was used for a pre-adapting light in the dark adaptation experiments. It provided 6.7 log scotopic td and was viewed for $3 \mathrm{~min}$. The beam of each of these lights was wide enough to illuminate uniformly the entire surface of a half sectioned ping-pong ball placed over the right eye. This provided uniform illumination of the entire retina and obviated the necessity for a distinction between regions of the retina stimulated by focal, and those excited by stray, light. Though visual detection can, photopupil motion cannot, make this distinction. The failure to take this precaution often makes it difficult to interpret the result of experiments on the pupil light refex, and is one justification for repeating experiments here which are otherwise similar to those described by others (SCHWEITZER and BOUMANN, 1958; SCHUBert and Thoss, 1967; WeBster et al., 1968; WeBster, 1971). A cylindrical rubber tube surrounded the right eye to prevent any of the stimulus from leaking to the unexposed (left) eye. 
The photopupil response was recorded by an infrared television pupillometer (GrEen and MAASEIDVAAG, 1967), the details of which are described elsewhere. Briefly, the left eye was diffusely illuminated with a tungsten lamp (S3) in whose beam was inserted an infra-red filter (F3 Wratten No. 89) and the infrared image of the iris and pupil was viewed with a television camera. The scanning spot of the camera swept across the image of the eye and a negative pulse appeared wherever the pupil interrupted the scan. The number of negative pulses was counted by an electronic counter and an analog output, linearly related to the diameter of pupil, was read out on a strip chart recorder. A metal artificial pupil of known size replaced the subject's pupil for calibration. One centimeter vertical deflection on the chart was adjusted to represent $1.0 \mathrm{~mm}$ dia. change of pupil and the strip chart recorder was run at a speed of 50-125 mm/sec. (The anterior segment of the eye was simultaneously monitored on the closed circuit television screen, which made it easy not only to align and focus the camera on the subject's eye, but also to detect a number of possible fixation and lid artifacts and to correct for them as they occurred.)

Prior to the experiment, the biting bar was properly positioned to bring the subject's head and eyes into alignment. The right pupil of the subject was fully dilated by two drops of $1 \%$ tropicamide.

\section{Light adaptation}

Subjects were first dark adapted for $30 \mathrm{~min}$. Following realignment in the apparatus, responses were recorded to a series of test flashes beginning at threshold and increasing in intensity in 0.3 or $0.5 \log$ stept until no further increase in response amplitude was found, or the test flash could be made no brighter. Suitable intervals between flashes were always allowed to insure that the retina maintained its fully dark adapted sensitivity. Next, the very weakest background light was turned on, the subjoct adapted for several minutes to this background; the test flashes were then presented in the same sequence and spacing as before. The process was repeated again at a background 0.5 or $1.0 \mathrm{log}$ units brighter, and in this way, the experiment proceeded to higher and higher backgrounds. At the very brightest backgrounds the pupil approaches its minimum diameter even without a test flash (ALPERN and OHBA, 1972). At these intensities, the iris muscles appear to saturate; even the most intense flash evokes no response. We terminated out experiments at background levels about $1.0 \mathrm{log}$ units below this level.

In some special experiments, other adaptation and test conditions were employed: they will be described in detail below.

Dark adaptation experiments were done in two ways: (1) After full rhodopsin bleaching and alignment in the pupillometer, test flashes of various intensities were presented in the attempt to elicit a response near some arbitrarily selected criterion (usually $0.5-1.0 \mathrm{~mm}$ ). The experimenter adjusted the filters in front of the test flash, attempting to estimate for the time in the dark at which the flash was presented what filter would be needed to obtain the selected criterion. Sometimes, of course, his estimates were erroneous but after several runs of this kind, a fair accuracy of prediction was reached (within the precision of $\pm 0 \cdot 1 \mathrm{~mm}$ ), and enough experimental points could be obtained to plot a pupillomotor dark adaptation curve, showing the intensity of the test flash required to obtain the criterion response at various moments in the dark after a full bleach. The motor on the strip chart recorder was started at the moment the bleaching light was extinguished, and since the paper moved continuously throughout dark adaptation, an accurate recording was obtained of the moment in the dark that the test flash was presented. After each response, the filter density used to obtain it was pencilled on the record. The records were processed by selecting those responses which fell within the arbitrary criterion and plotting the $\log$ of the flash intensity as a function of the time in the dark after the full bleach.

(2) In the second method, the bleaching exposure and recording were the same as that used in (1). After the adaptation light was turned off (at precise moments in the dark, usually $1 \cdot 0,2 \cdot 0,3 \cdot 0,4 \cdot 5,6 \cdot 0,7 \cdot 0,10 \cdot 0$, $12 \cdot 0,15 \cdot 0,20 \cdot 0,30 \cdot 0$, and $40.0 \mathrm{~min}$ ), the test flash was given to the right eye, and measurements of photopupil response were made from the left. When a relatively bright flash was used, intervals between flashes had to be lengthened to obviate effects of the test flash itself on the dark adaptation curve. In this method, usually only one intensity of test flash was used in any given run.

In subsequent runs different flash intensities were used and after a sufficient number of such experiments had been completed, a dark adaptation curve could be determined in the manner of ALPERN et al., (1959), (i.e. by plotting a separate curve relating the pupil response amplitude to time in the dark for each flash intensity and then by interpolating from this family of curves the flash intensity at any moment in the dark required to obtain a fixed response criterion).

The dark adaptation curves obtained by these two different methods were quite equivalent and this result completely validates the experiments of ALPERN et al., (1959). Day to day differences in the absolute level of the curve were found, but the form of the curve remained the same over the more than 12 months that the experiments were carried out. The dark adaptation curves illustrated in this paper were obtained by the first of the two methods, since with it, the curve can be obtained in one sitting once enough information was available that accurate threshold estimates were possible. To obtain the curve showing the equivalent background as a function of time in the dark, it proved important to measure both light and dark adaptation curves in the same experimental run. The matched responses shown in Fig. 7, however, were obtained by the 
second method since this allowed us to study a wider range of response amplitudes in the course of dark adaptation after a full bleach.

Dark adaptation curves have been measured on five young adult subjects and light adaptation on five. Only two subjects were common to both sets of measurements and studies of equivalence of bleaching and backgrounds were made only on them. All of the eight subjects responded in similar ways to comparable experiments and the results we report seem to be reasonably general for the normal population. Individuals differ, of course, in the size of their pupils measured under any fixed set of conditions, and to a lesser extent, in the absolute values of the latency and amplitude of their responses to a given flash. In the way responses are changed by bleaching and by background, they are, however, quite similar. In light adaptation, the response amplitude vs. $\log$ I curve has a somewhat variable slope near thresholds among different subjects. Our major subjects were all particularly sensitive to small changes in flash intensity at these levels. Increment thresholds are more accurate on such subjects than on those whose response - log I curve has a shallow slope (Webster et al., 1968).

In this paper response amplitude refers to the maximum change in pupil diameter evoked by the test flash, (cf. Fig. 7 for some representative responses). This was measured on the pupillogram as the distance between the base-line and the smallest pupil diameter on the record. In the analysis we have neglected the fact that with different backgrounds (and bleachings) the base-line changes in a way which is systemmatically analyzed in the preceding paper (ALPERN and OHBA, 1972). In that paper it is shown that over the range of backgrounds studied here, the base-line pupil size is almost always considerably larger than those diameters at which the iris muscles saturate. Hence, neglecting this change in base-line leads to difficulty only to responses to intense flashes at the very brightest backgrounds and in the first minute in the dark after a full bleach (but see below).

\section{RESULTS}

\section{Light adaptation}

Figure 2A shows the results of light adaptation experiments on a single observer and a single experimental session. The results are quite characteristic. The ordinates in this figure show the amplitude of the response and the abscissae shows the log of the test flash intensity expressed as fractions of the brightest available flash. The parameter in this figure is the luminance of the background (in photopic td). Near threshold the response amplitude increases nearly linearly with the log of the flash intensity; however, very intense flashes are not proportionally as effective so the entire curve, in general, is quite non linear. Backgrounds progressively displace the curves at low intensities to the right along the abscissa and also reduce the total range of response evoked, even by the brightest test. This latter effect may well represent limitation imposed by the muscle (cf. AlPERN and OHBA, 1972). This is a complexity we wish to avoid, and to obviate it, we here confine the analysis to responses equal to or smaller than about $1.0 \mathrm{~mm}$.

The mean results of six different sessions on this subject with such weak responses (each point the mean of 10-20 measurements given equal weight) are shown in Fig. $2 \mathrm{~B}$. These results, for one of our subjects, (typical of all the others) is characterized by a relatively steep slope of the amplitude log I curve near threshold and the family of curves shown here are quite similar to those obtained by WeBsTER et al. (1968) with a $74^{\circ}$ field. Our analysis is, however, somewhat different.

This is shown by the triangles in Fig. 3 which were obtained in essentially the same experiment (though on a different subject). Results like those in Fig. 2B have been analyzed by determining the values of $\log \Delta I / \Delta I_{o}$ required to produce a small change of pupil size $(0.5 \mathrm{~mm})$ at each background. This is done by drawing a horizontal line across the figure and measuring on the abscissa the difference in the log of the test intensity needed to evoke a $0.5-\mathrm{mm}$ response at a given background compared to the intensity required in the dark. This value is plotted (ordinate) as a function of the background intensity (abscissae) in scotopic td. The solid smooth curve drawn through these triangles has a general form which 
is used to describe all the increment threshold results of this paper. It is made up of two curves, each of which has the equation

$$
\log \frac{\Delta I}{\Delta I_{o}}=\log \left(I+I_{D}\right)+\mathrm{k}
$$

$\Delta I / \Delta I_{o}$ represents threshold elevation, and $I$ the background intensity. $I_{D}$ is a constantthe dark light or eigengrau (BARLow, 1957) and $\Delta I_{0}$ is the pupillomotor full field absolute threshold of the fully dark adapted eye, here always arbitrarily set equal to unity; $k$ is a proportionality constant related to the Fechner constant.
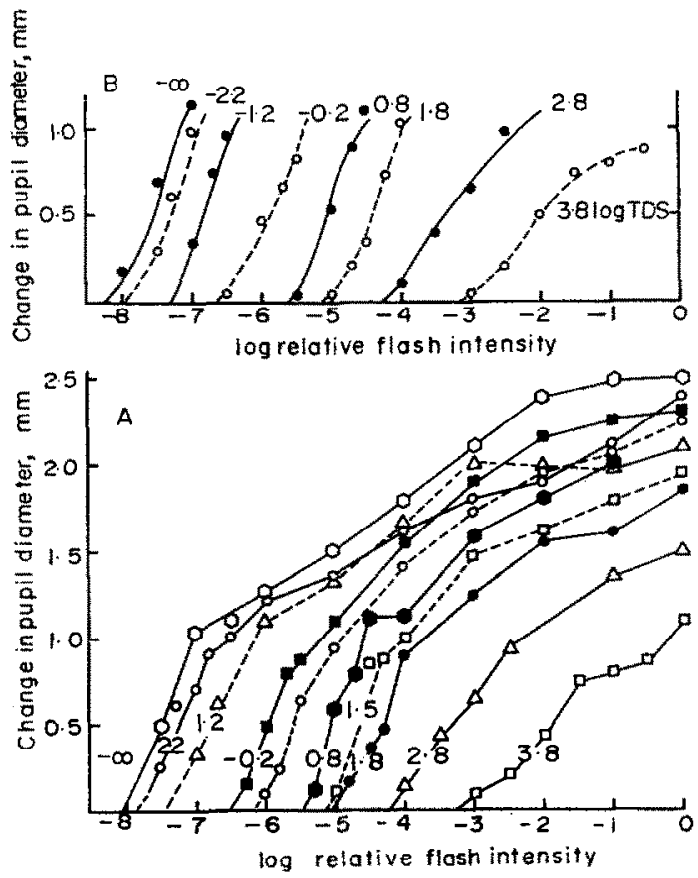

FIG. 2(A). Pupil responses amplitude (in $\mathrm{mm}$ ) is plotted as a function of test flash intensity. The parameter is background retinal illuminance and its intensity is indicated on each curve in log photopic td. The ordinates show changes in pupil size, the abscissae show the log of the flash intensity relative to the maximum value atbitrarily set equal to $1 \cdot 0$. The results are from a single experimental run with subject M.O. (B). The mean of responses less than $1.2 \mathrm{~mm}$ are included. Note the steep response $\log$ I relation near threshold. This result is characteristic of the subjects we studied.

The lower left of the two sets of curves in Fig. 3 is attributed to responses resulting from excitation of rods. The evidence for this view is two-fold: (i) In full dark adaptation, the absolute threshold for the pupil response with full field illumination is very nearly identical to the absolute threshold for vision (SCHWErTzER, 1955). On four subjects, BURKE and OGLE (1964) found the average pupil threshold to be 0.22 (range 0.14-0.3) log units brighter than for vision. Our own measurements confirm this. Since the rod threshold measured psychophysically in full dark adaptation is some 3.0-4.0 log units below cone threshold, it is clear that the pupil absolute threshold in full dark adaptation and full field illumination is due to 
rods and rods alone. (ii) The lower curve drawn up from the absolute threshold follows the principle of univariance (RUSHTON, 1970). Accordingly, varying the wavelength of the background field causes only a lateral shift of the curve on the intensity axis and the amount of the lateral shift is determined only by the action spectrum for rod vision (cf. STILES, 1939). This is shown by the squares in Fig. 3, which were obtained in exactly the same way as the triangles, with the exception that a Wratten No. 92 filter (dominant $\lambda=646 \mathrm{~nm}$ ) was placed in the background field. The intensity of the background for the squares has been equated

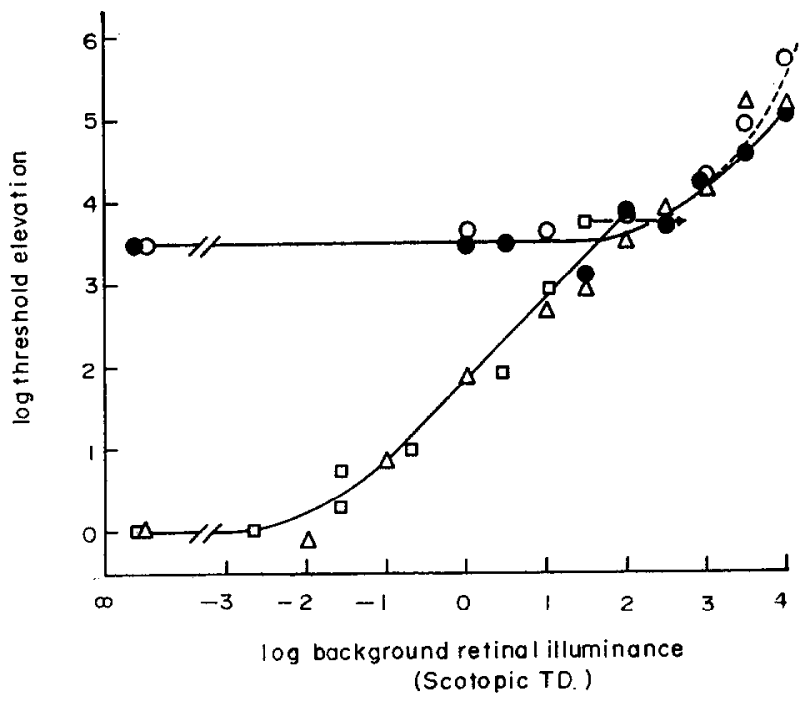

FIG. 3. Increment threshold for $0.5 \mathrm{~mm}$ criterion response for subject W.M. Triangles show results for a white test on white background, beginning in full dark adaptation. Squares show the results for same test and similar adaptation conditions, but the test is superimposed on a red background. The squares have been shifted according to the scotopic transmittance of the red (Wratten No. 92) filter in the background field. The arrow drawn from the square at 1.5 $\log$ scotopic td. shows the amount this point would be shifted to adjust for the photopic transmission of this red filter. The circles show the results for a white test taken between 5-10 min in the dark after a full bleach when the cones had reached full dark adapted threshold. The test intensity in these cases was always kept above cone threshold, but below rod threshold as inferred by extrapolation of the rod dark adaptation curve (for details see text). Open circles, white test; closed circles, red test equated for photopic transmission of the red filter.

for scotopic transmission of the red filter for our light source. Within the limits of experimental error, the squares agree with the triangles as long as they fall on the lower curve. The square at the highest level studied ( $1.5 \log$ scotopic td) falls significantly above this curve. This is because it belongs more properly to the upper, rather than to the lower, curve.

The upper of the two sets of curves is attributed to responses resulting from the excitation of cones. The evidence for this view is: (i) After full bleaching, the absolute threshold for cones recovers in about $5 \mathrm{~min}$ and cone remains more sensitive than the rods for another 5-10 min. When the rods become more sensitive, the log threshold falls exponentially on a curve with a time constant of about $400 \mathrm{sec}$. Work on rod monochromats (RUSHTON, 1961 ; AlPERN, 1971) suggests, and RusHTON's (1965b) experiment on the normal eye document 
that during the interval, 5-10 min in the dark, when the normal cone threshold remains constant (and more sensitive) than the rod threshold, the latter is falling on the same (extrapolated) exponential curve. Hence, it becomes possible to study the cone increment threshold pupillomotor curve-even with full field illumination-by first bleaching away all the retinal visual pigments, making the measurements during the time interval, 5-10 min in the dark, while the cone threshold is fully recovered and below the rod threshold and by confining the test flash intensities to the range of illumination levels above the cone threshold and below the extrapolated exponential curve which shows the recovery of rod threshold. The increment threshold for pupillomotor response obtained in this way is shown by the open and closed circles in Fig. 3. [The open circles were obtained for a white test flash and the closed circles for a red (Wratten No. 92) test flash.] The agreement of these results with the upper of the two curves drawn through the triangles is evidence that the latter is attributed to excitation of cones. (ii) The action spectrum for this curve (for both test flash and background) is that of the photopic spectral sensitivity curve. For a test flash this is shown, not only by the fact that both the open and filled circles agree with one another and with the triangles when they have been equated (as in Fig. 3) for the photopic transmission (for the test flash source) of the red filter, but also by a similar agreement (not shown in Fig. 3) for these background levels when the red test flash is presented in adaptation conditions identical to those for which the triangles were obtained. This last result confirms AlexANDRIDIS and KOEPPE (1969) who used yellow and blue tests. Similarly, for colored backgrounds this is shown by the fact that different curves for different wavelengths of the background all fall together when equated for photopic transmission of the filters. (In Fig. 3 the square at the highest background intensity tested-1.52 log scotopic td-falls significantly off the lower curve; it falls on the upper curve, however, if equated for the photopic transmission of the red filter. This equation is shown by the tip of the arrow drawn to the right of the square at $1.52 \mathrm{log}$ scotopic td which represents the amount the square must be shifted to be equated for the photopic transmission of the red filter for the background light source.)

The curves drawn in the way just described are used to fit all the increment threshold data of this paper. In two ways, this procedure oversimplifies our results.

(i) At the very highest backgrounds there is a systematic deviation in the sense that the pupillomotor threshold is higher than the smooth curve drawn as outlined above. This deviation becomes more and more serious, the larger the response criterion. Examination of the raw records reveals that this difficulty is due to the fact that the very bright backgrounds have produced such a miotic pupil that saturation of the muscle, rather than the retinal cone signals, for example, is imposing the limitation which elevates the pupil threshold. The dotted line is drawn through the high intensity result in Fig. 3 to show this trend. (ii) A second difficulty is a systematic tendency for the pupillomotor sensitivity to fall below the smooth curve in the region of transition between the lower and the upper curves. This tendency in Fig. 2 is revealed in all of our curves, both for real and bleaching backgrounds. It is attributed to the fact that for both rods and cones, the pupillomotor threshold is very slightly less sensitive than the visual threshold. Consequently, in regions where rod and cone sensitivity is very nearly the same, a light which is too weak to excite a pupillomotor response by the rod (or the cone) system alone can do so when both are excited together.

\section{Dark adaptation}

The pupillomotor dark adaptation curves of ALPERN et al. (1959) have been criticized by BRECHER (1959) because they were measured not in a single session by adjusting the flash intensity for some criterion response, but over a series of sessions in each of which only one flash intensity was employed. In the dark adaptation experiments shown in Fig. 4, we, therefore, have repeated the study of the pupillomotor dark adaptation in a manner as similar as possible to the way dark adaptation curves are measured psychophysically. The 
squares, triangles, and circles in this figure show three independent repetitions on each of two subjects of the flash intensity required for a criterion response $(0.5 \mathrm{~mm}$ contraction for the subject illustrated in the upper set of curves, $0.8 \mathrm{~mm}$ for the subject shown in the lower set) in single experimental runs. In each run the visual pigments were bleached away, and after going into the dark, the experimenter adjusted the flash intensity to produce some fixed response criterion, changing the intensity as quickly as possilbe and making the best possible estimate of the flash intensity required for the criterion response at the moment the flash was presented. When this estimate was right (i.e. within $\pm 0.1 \mathrm{~mm}$ ), the intensity

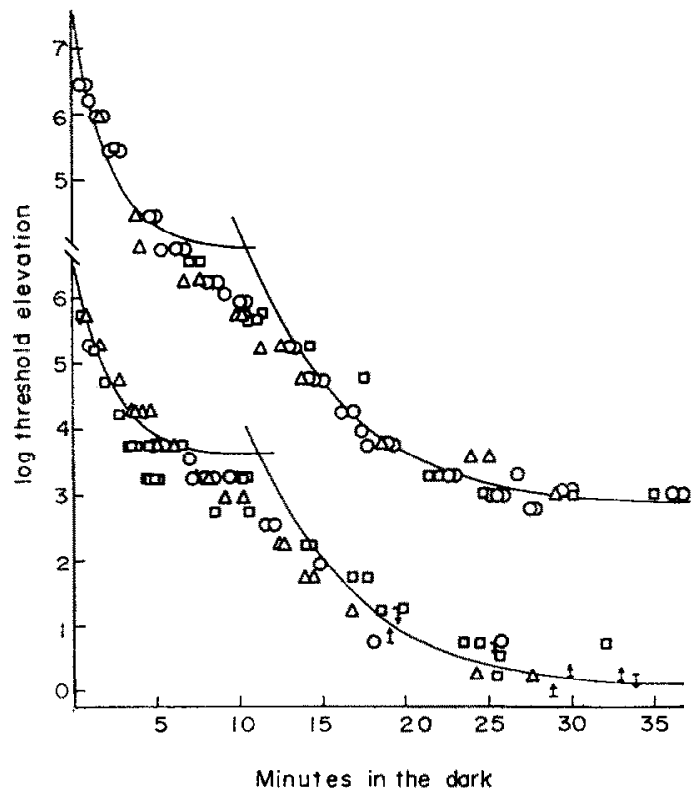

Fig. 4. Dark adaptation curves in three sucessive runs after full bleaching required for $0.5 \mathrm{~mm}$ criterion (obs. R.A. above) and for $0.8 \mathrm{~mm}$ criterion (obs. M.O. below). The responses recorded by squares, circles and triangles represent flash intensities which evoked responses within $\pm 0.1 \mathrm{~mm}$ of the criterion in one of the three runs. The responses shown by the arrows were flashed at the density shown by the tail; they fall outside of the criterion $\pm 0.1 \mathrm{~mm}$ but within the criterion $\pm 0.3 \mathrm{~mm}$. The direction of the arrow shows the direction in which the intensity of the flash must be changed in order to meet the criterion.

required for criterion is plotted as a triangle, square or circle in Fig. 4. If the responses exceeded this limit, but not by more than $\pm 0.3 \mathrm{~mm}$, the point is plotted as an arrow, the tail of which shows the flash intensity and the tip its direction (pointing up if the flash was too dim to evoke the criterion, down if too bright).

Except as noted below, the results in Fig. 4 (and all our other pupillomotor dark adaptation measurements) agree quantitatively with the results of ALPERN et al. (1959) over the $40 \mathrm{~min}$ time in the dark after a full bleach studied here. They are best fit by two exponential curves. The first of these has a time constant of two minutes and follows the same form as the recovery of the cone visual pigments, chlorolabe and erythrolabe, as well as the change in log cone threshold after a full bleach. The second has a time constant of $400 \mathrm{sec}$ and the 
same form as the recovery of rhodopsin after a full bleach and the change in log threshold of the rods as measured psychophysically. We, therefore, attribute these curves, respectively, to the recovery, first of cones, then of rods. The results in Fig. 4 (like comparable ones in Fig. 3) agree well with the smooth curves except in the neighborhood of the transition from the upper (i.e. cone) to the lower (rod) curve. There the pupillomotor sensitivity is signifcantly greater than predicted from the curves. The best explanation for this is undoubtedly the same as that offered for the analagous result in Fig. 3: Because the pupillomotor threshold is just larger than the visual threshold, the pupil threshold first follows cone recovery then rod recovery quite closely, except in the range where the sensitivity of both rods and cones is nearly the same. In this range a light which is too dim to evoke a pupil response if only the rods (or the cones) by themselves were suprathreshold (for vision), is capable of evoking a pupil response at these time intervals because both rods and cones are suprathreshold.

This effect is not obvious in the results of ALPERN et al. (1959), presumably because the stimulus flash $\left(21^{\circ}\right)$ was considerably smaller than that used here. SCHwErTzeR's (1956) results suggest that the entire retina is capable of summating pupil responses. Full field retinal excitation tends to minimize the conspicuousness of the rod-cone transition in photopupil studies of this kind in comparison to smaller test areas, probably because under the former conditions every retinal receptor has been excited.

\section{Pupillomotor equivalent background}

The results of all of the above experiments show a similarity between the process of dark (and of light) adaptation for vision and photopupillary motion. In vision it was suggested by STILES and CRAWFORd (1932) and by CRAwFord (1947) and substantiated, with additional experiments by RusHToN (1965a), that the processes of light and dark adaptation could be unified with the concept of the equivalent background of the bleach. These experiments (cf. especially RUSHTON and WeSTHEIMER, 1962) show that the regulation of sensititivy is a property of the nerve pools rather than of the pigments. It, therefore, seems important to determine the extent to which this concept can be extended to the photopupil response. This question is investigated in the present section.

The experimental equivalence of bleaching and backgrounds for the photopupil response is obtained in the manner illustrated in Fig. 5A. In this experiment, following a full bleach, a photopupillary dark adaptation curve $(0.5 \mathrm{~mm}$ criterion) was obtained in the same way as those in Fig. 4. The results (single experimental session) are shown in the curve at the left. After about $40 \mathrm{~min}$ in the dark, light adaptation experiments were carried out. The subject first adapted to the dimmest background $(-2.2 \log$ td) and the test flash was then adjusted for criterion response as shown. The background intensity was then increased once more, the process again repeated, and in this way the entire increment threshold curve on the right was obtained. The full dark and light adaptation curves were in this way obtained in a single experimental session. At each moment in the dark the equivalent background of the bleaching was determined in the way shown by the dotted lines in Fig. 5 for example, which is drawn to determine the value at $14 \mathrm{~min}$ in the dark. At this moment after full bleaching, it is seen from the left hand curve in this figure that the absolute pupillomotor threshold has been elevated by $2.35 \mathrm{log}$ units. To establish the equivalent background of the bleaching at $14 \mathrm{~min}$, we need to know what background raises the pupillomotor threshold by $2.35 \mathrm{log}$ units. To determine this, we follow the horizontal dotted line from the left to the right hand 
curve and read off the anti-log of the real background at which this horizontal line strikes the smooth right hand curve. It is $1.07 \mathrm{td}$.

The process outlined above can be repeated at other time intervals in the dark; and, the entire curve showing the change in equivalent background after bleaching can thus be generated. The curves shown by the solid lines in Fig. 6 are examples from single experimental runs on each of two observers. Successive experiment on the same observer show differences from one run to the next of about the same degree as that shown in Fig. 6 between observers. The absolute level, in particular, may differ from run to run by as much as $0.5 \log _{10}$ units.

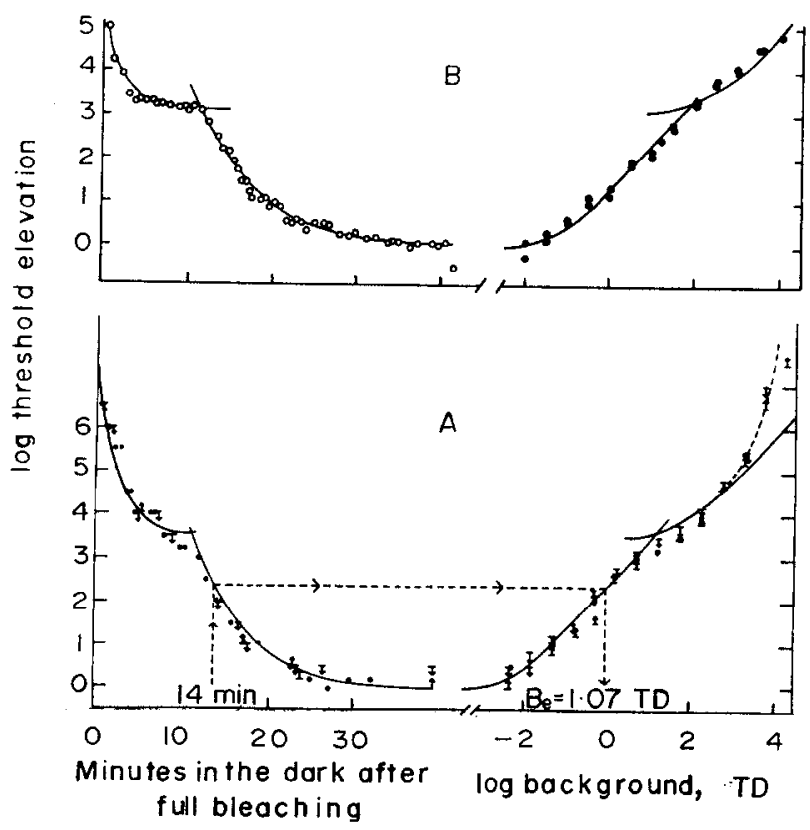

FIG. 5(A). Pupillomotor equivalent background of the bleach for a single experimental run for subject R.A. (criterion $0.8 \mathrm{~mm}$ ). The dots show responses which meet the criterion $\pm 0.1 \mathrm{~mm}$ and arrows those which exceed this limit but not beyond $\pm 0.3 \mathrm{~mm}$ with the same convention as Fig. 4. Left hand curve, dark adaptation; right hand curve, increment threshold. The curves are drawn through the results in the way specified in the text. The dotted lines illustrate the way the equivalent background of the bleach $(1.07 \mathrm{td})$ is obtained in the dark at $14 \mathrm{~min}$ after a full bleach. 5(B) The analogous psychophysical experiment on this same subject. The test was $4.5^{\circ}$ blue (dominant wavelength $470 \mathrm{~nm}$ ) flash, $100 \mathrm{msec}$ duration centered $18^{\circ}$ in the temporal retina of the right eye. Full bleach was achieved by $3 \mathrm{~min}$ of exposure to $6.3 \mathrm{log}$ scot td.

The form of the rod and cone portions, otherwise, are no different and the discontinuity occurs at about the same moment in the dark, in all these curves. The rod exponential has a time constant of $400 \mathrm{sec}$ and the cone exponential, $120 \mathrm{sec}$.

\section{Psychophysical quivalent background}

The analogous psychophysical experiment to the pupil experiment of Fig. 5A is shown for this same subject in Fig. 5B. Dark and light adaptation curves were measured for the peripheral retina $18^{\circ}$ temporal from the fixation point for a $4.5^{\circ}$ blue (dominant wavelength 
$470 \mathrm{~nm}$ ) test flash $100 \mathrm{msec}$ in duration. Dark adaptation was measured after $190 \mathrm{sec}$ exposure of $6.3 \mathrm{log}$ scotopic td in a circular field twice as large as the test flash and concentric with it. The light adaptation was obtained by varying the intensity of this same field acting as a steady background. Data such as those illustrated in Fig. 5B have been used to infer the psychophysical equivalent background of the bleach in the manner described for Fig. $5 \mathrm{~A}$ and the results of single experimental runs for each of these subjects is shown by the dotted curves in Fig. 6. No adjustment or scaling of the curves has been made. The agreement of the dashed and the solid curves, in spite of the wide difference of the experimental conditions under which they were obtained, is as close as that obtained (either psycho-

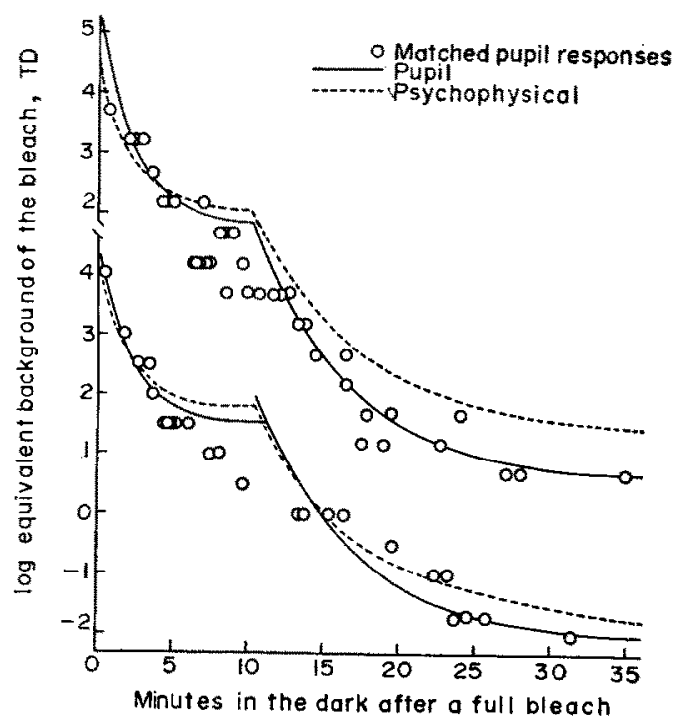

FIG. 6. Equivalent background of the bleach in single experimental runs for subject R.A. (above) and M.O. (below). The solid smooth curve was obtained for the photopupil response in the way shown in Fig. 5(A). The open circles show the log of the real background intensities at which a flash of a given intensity evoked a response which matched in the way shown in Fig. 7 to the response obtained at that moment in the dark (abscissae) after a full bleach by the same flash intensity and in the same experimental session. Dotted curve shows the equivalent background of the bleach obtained psychophysically in a single experimental session about a year later. All results in this figure are fixed without any arbitrary shifting.

physically or photopupillomotorically) in a single repetition of the identical experiment. The clear inference is that within the limits of experimental error, the equivalent background for vision and the photopupil response is the same.

\section{Waveform comparison}

For vision, equivalence of backgrounds unifies adaptation experiments employing a variety of test flash areas. To obviate complications from scattered light photopupillary motion has been tested here with a flash covering the entire retina and we have examined equivalence of backgrounds for the waveform of the photopupil responses to flashes differing in intensity.

Figure 7 shows this comparison for one subject. The dashed line connecting the dots is the form of the pupil constriction evoked by a flash of a fixed intensity (scale to the extreme 
right) on a real background, whose intensity is indicated just to the right of the waveform. Each such wave is superimposed on a solid curve which shows a matched response obtained at a given time in the dark after a full bleach by the identical flash. The extent to which the two curves superimpose is the extent to which the two responses match. In Fig. 7, responses matched in this way have been arranged in columns so that in any given column, all the solid curves have been obtained at very nearly the same time in the dark after the bleach. (This is only approximately true, so that the exact moment the solid curve response was evoked is shown just below its waveform and slightly to the left.) The responses are arranged in rows according to the intensity of the test flash which evoked them. The extent to which background equivalence holds, independent of waveform and flash intensity, can be seen,

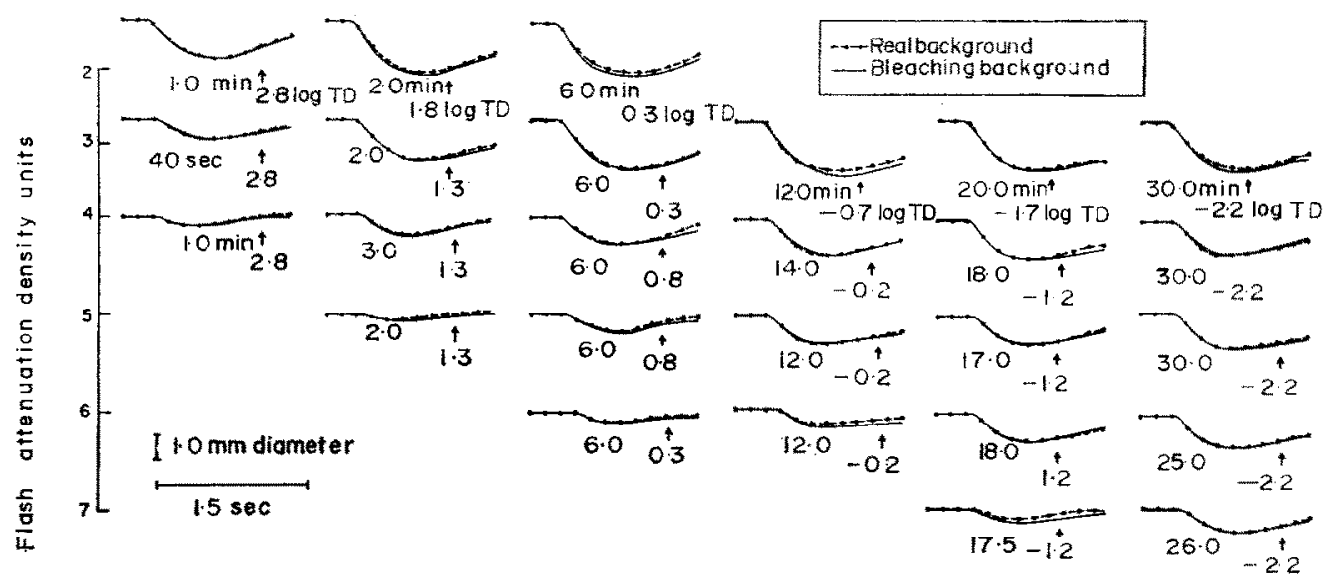

Fig. 7. Matching of responses on bleaching backgrounds (solid curve) and real backgrounds (dotted curve) for subject M.O. The responses were obtained in different experimental sessions about six months after the results in Fig. 6 for this subject. The vertical columns have been arranged to show responses that were obtained in very nearly the same moment in the dark after a full bleach (although in a different experimental session). Each matched response in a bleaching background has been evoked by the same flash intensity as its counterpart on the equivalent background. The flash intensity for each horizontal row is the same and the Wratten No. 96 filter density placed in the test beam is shown on the scale at the extreme left. For each pair of matched responses, two numbers are placed immediately beneath them. One shows the time in the dark after the full bleach that the response shown by the solid line was obtained, the other shows the background intensity (log photopic td.) upon which the dotted response was evoked. Each record starts simultaneously with the onset of the stimulus flash.

therefore, in any given column by the extent to which matched responses of the dashed curve were obtained on the same intensity background. This is usually (and with the precision of $0.50 \log$ unit background intensity, always) the case. Figure 7 suggests the equivalence of backgrounds is valid for each aspect of the pupil response, latency waveforms and amplitude, not only as in psychophysical experiments (at threshold), but also for responses evoked by flashes several log units above threshold as well.

Finally, the extent to which the background equivalence, obtained by matching responses in the way shown in Fig. 7, varies with time in the dark in comparison to the fixed criterion matching used to generate the curves in Fig. 5A is shown by the open circles in Fig. 6. These matched responses were evoked in the same experimental session as the solid curve in that figure was obtained, and the agreement-except as noted above in the region of transition 
between the rod and cone curves-is clear. The results in Fig. 7 were obtained in different experiments several months later. They too fit these results in Fig. 6 for this observer by the same amount, but they must first be shifted vertically $0.5 \log _{10}$ units, as indeed is typical of the variability from one experimental session to the next.

\section{DISCUSSION}

The results in Fig. 7 suggest a near identity of the pupil responses evoked by the same flash on bleaching background and on its equivalent real background. The fact that when two such responses are matched for amplitude, the entire waveform-latency and other time characteristies-also match is surprising, in view of the subtle differences in time characteristics of matched ERG $b$ waves found for rat (CONE, 1964) and cat (MAFFEI and POPPELE, 1968). However, the agreement found in Fig. 7 may be deceptive. Our pupillometer has a minimum sampling interval of $16.7 \mathrm{msecs}$ and this sets an upper limit on the precision of the match of time characteristics that can be achieved in these experiments. Furthermore, a good deal of the subtlety of the differences between time characteristics of the retina in the course of bleaching and backgrounds might well be masked by the sluggish time resolution of the iris smooth muscles. In view of the remarkable recent literature using systems analysis of the light reflex (Stark and Sherman, 1957; Clynes, 1961; Green, 1964; WeBster, 1971; VARJÚ, 1964; TROELSTRA, 1968), it is surprising that there is not yet sufficient information with which to write a transfer function that would allow us to simulate the time characteristic of the iris muscles, much less of the central nervous system components of the light reflex. DENNISON (1966) has recently shown that the isometric response of the cat iris sphincture in vitro to a step of electric current has a latency of $0.2 \mathrm{sec}$; undoubtedly, muscle delays of this same order are included in our in vivo responses.

Hence, the combination of a rather slow time resolution of the pupillometer and a sluggish response of the iris muscle may hide the subtle differences in time scaling produced by bleaching and backgrounds and revealed by the ERG. We have tried to confirm this suspicion by a more quantitative analysis of the time characteristics of pupil response latency than the one shown in Fig. 7. The method was exactly equivalent to that used by ALPERN (1968) to analyze visual latency revealed by experiments on the Pulfrich stereophenomenon. Although the expected discrepancy of about the right order between the effects of bleaching and backgrounds was, in fact, found, the analysis depended upon a rather arbitrary shifting of latency-response curves (for minimum scatter) to obviate the $200 \mathrm{msec}$ or so delay in the iris muscle. The uncertainty of what constitutes "minimum scatter" in the process of the arbitrary shifting can only be removed by averaging responses from a good many more experiments than we have so far completed. In the case of real background, this is experimentally straightforward, but technical complications arise with bleaching backgrounds with our present computer facilities. It seems unwise at this point, therefore, to press the analysis further than the data justify and we only wish to emphasize here that the similarity in the time characteristics of responses evoked by the same test on real and its equivalent bleaching background shown in Fig. 7 may, in fact, be in part due to the slow pupillometer and the even slower motor response that is being studied.

Thus, all of the results of this paper are consonant with the view that backgrounds and bleaching influence photopupillary motion sensitivity in the identical way they influence visual sensitivity. The simplest explanation is that the nerve pathways which underlie these two functions are identical up to at least the level in the retina where regulation of sensitivity in adaptation has been achieved. These experiments cannot in themselves exclude, however, 
the less parsimonious alternative that parallel channels undergo identical adaptation operations for these functions, though this seems a very wasteful way of utilizing valuable retinal space for a function (adaptation of the light reflex) which must certainly be regarded of limited survival value.

Acknowledgements - Assisted by a grant EY-00197-13 from the National Eye Institute. We thank WiLLIAM MORRISON for continuing help in the early stages of this work including carrying out the experiments the results of which are shown in Fig. 3, Dr. F. MAAserdvaAg for assistance in various ways and our subjects for patient and generous donation of their time. Dr. OHBA was assisted by the Walter B. Parker Fund of the University of Michigan.

\section{REFERENCES}

Alexandridis, E. and Dodt, E. (1967). Pupillenlichtreflexe and Pupillenweite einer Stäbchenmonochromatin. Albrecht v. Graefes Arch. Ophthal. 173, 153-161.

AleXANDridis, E. and KoEPPE, E. R. (1969). Dis spektrale Empfindlichkeit der für den Pupillenlichtreflex verantwortlichen Photoreceptoren beim Menschen. Albrecht v. Graefes Arch. Ophthal. 177, 136-151.

ALPERN, M. (1968). A note on visual latency. Psychol. Rev. 75, 260-264.

AlPern, M. (1971). Rhodopsin kinetics in the human eye. J. Physiol., Lond. 217, 447-471.

AlPERN, M. and Benson, D. J. (1953). Directional sensitivity of the pupillomotor photoreceptors. Am. J. Optom. 30, 569-580.

Alpern, M. and CAMPBell, F. W. (1962). The spectral sensitivity of the consensual light reflex. J. Physiol., Lond. 164, 478-507.

AlPERN, M., KrTAI, S. and ISAACSON, J. D. (1959). The dark-adaptation process of the pupillomotor photoreceptors. Am. J. Ophthal. 48, 583-593.

AlPERN, M. and OHBA, N. (1972). The effect of bleaching and backgrounds on pupil size. Vision Res. 12, 943-951.

BarLow, H. B. (1957). Increment thresholds at low intensities considered as signal/noise discriminations. J. Physiol., Lond. 136, 469-488.

BRECHER, G. A. (1959). Discussion of "The Dark-adaptation process of the pupillomotor photoreceptors". Am. J. Ophthal. 48, 592.

BURKE, D. W. and OGLE, K. N. (1964). Comparison of visual and pupillary light thresholds in periphery. Archs. Ophthal. 71, 400-408.

Clynes, M. (1961). Unidirectional rate sensitivity: A biocybernetic law of reflex and humoral systems as physiologic channels of control and communication. Ann. N.Y. Acad. Sci. 92, 946-969.

CONE, R. A. (1964). The rat electroretinogram. I. Contrasting effects of adaptation on the amplitude and latency of the $b$-wave. J. gen. Physiol. 47, 1089-1105.

CRAWFORD, B. H. (1947). Visual adaptation in relation to brief conditioning stimuli. Proc. R. Soc. B. 134, 283-302.

Dennison, B. L. (1966). A mathematical model for the isolated cat iris sphincter muscle. Proc. of 19th ann. Conf. Engng. Med. Biol. 194.

GREEN, D. G. (1964). An investigation of the Dynamics of the Pupil Light Reflex. Ph.D. thesis, Northwestern University.

Green, D. G. and MaAseidvaAg, F. (1967). Closed-circuit television pupillometer. J. opt. Soc. Am. 57, $830-833$.

MAFFE, L. and Poppele, R. E. (1968). Transicnt and stcady state clectrorctinal responses. Vision Res, 8, 229-246.

Rushton, W. A. H. (1961). Rhodopsin measurement and dark-adaptation in a subject deficient in cone vision. J. Physiol., Lond. 156, 193-205.

Rushton, W. A. H. (1965a). Visual adaptation: The Ferrier Lecture. Proc. R. Soc. B. 162, 20-46.

Rushron, W. A. H. (1965b). The rod dark adaptation curve measured above cone threshold. J. Physiol. Lond. 181, 641-644.

Rushton, W. A. H. (1970). Pigments in anomalous colour vision. Br. med. Bull. 26, 179-181.

Schurert, E. and THoss, F. (1967). Der Einfluss verschiedener Adaptation auf die Schwelle sowie auf die Reizstärkeabhängigkeit von Latenzzeit und Amplitude am konsensuellen Pupillenreflex des Menschen. Pfügers Arch. ges. Physiol. 294, 28-39.

SCHWEITZER, N. M. J. (1956). Threshold measurements on the light refex of the pupil in the dark adapted eye. Documenta Ophth. 10,1-78.

Schwertzer, N. M. J. and Bouman, M. A. (1958). Differential threshold measurements on the light reflex of the human pupil. Archs. Ophthal. 59, 541-550.

Stark, L. and Sherman, P. M. (1957). A servoanalytic study of consensual pupil reflex to light. J. Neurophysiol. 20, 17-26. 
Stiles, W. S. (1939). The directional sensitivity of the retina and the spectral sensitivities of the rods and cones. Proc. R. Soc. B. 127, 64-105.

Stiles, W. S. and CrAwford, B. H. (1932). Equivalent adaptation levels in localized retinal areas. Rep. Discuss. Vision Phys. Soc. (Lond.) 194-211.

Troelstra, A. (1968). Detection of time-varying light signals as measured by the pupillary response. J. opt. Soc. Am. 58, 685-690.

VARJÚ, D. (1964). Der Einfluss sinusförmiger Leuchtdichteänderungen auf die mittlere Pupillenweite and auf die subjektive Helligkeit. Kybernetik 2, 33-43.

Webster, J. G. (1971). Pupillary light reflex: Development of teaching models. IEEE Trans. bio-med. Engng BME 18, 187-194.

Webster, J. G., Cohen, G. H. and Boynton, R. M. (1968). Optimizing the use of the criterion response for the pupil light reflex. J. opt. Soc. Am. 58, 419-424.

\begin{abstract}
The consensual photopupil responses to light flashes presented in uniform illumination to the entire visual field were recorded in full dark adaptation, over a gamut of intensities of ganzfeld backgrounds and in the dark after full bleach of all visual pigment in the retina. The equivalent background of such bleaching was found to be valid not only at the photopupillomotor threshold but also for flashes several log units suprathreshold (as judged by matching of the waveform of the pupillomotor response). The pupillomotor equivalent background is in reasonable agreement with its psychophysical counterpart, suggesting that the neural pathways for vision and photopupillary motion are common, at least to the level that retinal sensitivity adjustment in dark and light adaptation has been achieved.
\end{abstract}

Résumé-On mesure les réponses pupillaires consensuelles à des éclairs lumineux présentés sout forme d'un champ visuel total de luminance uniforme, après adaptation complète à l'obscuriés, dans une gamme étendue de luminances de ce champ et aussi dans l'obscurité après décoloration totale du pigment rétinien. Le fond équivalent d'une telle décoloration est valide non seulement au seuil photopupillomoteur, mais aussi pour des éclairs à plusieurs unités logarithmiques au-dessus du seuil (à en juger par la courbe de réponse pupillomotrice). L'équivalent du fond pupillomoteur est en bon accord avec sa contrepartie psychophysique, ce qui suggère une communauté de trajet nerveux pour la vision et le mouvement de la pupille, au moins au niveau étıdié de sensibilité rétinienne dans l'obscurité et à la lumière.

Zusammenfassung-Es wurde die Pupillenreaktion auf Lichtblitze, die das gesamte Gesichtsfeld gleichmäßig ausleuchteten, bei voller Dunkeladaptation aufgezeichnet. Diese Messungen wurden bei mehreren verschiedenen Intensitäten des Ganzfeldhintergrundes und im Dunklen nach völliger Ausbleichung der Sehstoffe der Retina ausgeführt. Der äquivalente Hintergrund einer solchen Ausbleichung gilt nicht nur düe die Schwelle der Pupillenreaktion, sondern auch für Lichtblitze, die einige Logeinheiten überschwellig sind (geschätzt nach Vergleich Wellenform der Pupillenreaktion). Der äquivalente Hintergrund für die Pupillenreaktion stimmt vernünftig mit dem entsprechenden psychophysischen überein. Das läßt vermuten, daß die Nervenbahnen für das Sehen und die Pupillenreaktion gleich sind, wenigstens bis zu der Stufe, bei $d$ t:r die Empfindlichkeitseinstellung der Netzhaut bei Dunkel- und Helladaptation erfolgt.

Резюме-Содружественные реакцин зрачков на световые вспышки, в виде равномерного освещения всего поля зрения, регистрировались, при полной темновой адаптации, при различных интенсивностях, на адаптируюшем фоне занимавшем все поле зрения, а так же в темноте, после полного обесцве чивания всего зрительного питмента в сетчатке. Был найден эквивалентный фон для такого обесцвечивания, который подходил не только при пороговых движениях зрачка, но так же для вспышек света на несколыко логарифмических сдиниц превышаюшую пороговую яркость (суждение на основания сравнения формы волны пупилломоторных реакций.) Пупилломоторный эквивалентный фон находится в удовлетворительном согласии с его психофизическим коррелятом. это позволяет предполагать, что нейральный путь для зренкя и двкжений зрачка общий; по крайней мере на том уровне, когда достигается приспособление чувствительности сетчатки к темновой п световой адагтация. 